\title{
Haplotypes in the urotensin II gene and urotensin II receptor gene are associated with insulin resistance and impaired glucose tolerance
}

Short title: Urotensin II and its receptor haplotypes

Kwok Leung ONG, BSc

Louisa YF WONG, PhD

Yu Bun MAN, MPhil

Raymond YH LEUNG, BSc

You-Qiang SONG, PhD*

Karen SL LAM, MD, FRCP, FRCPE, FRACP

Bernard MY CHEUNG, MA, MB BChir, PhD, FRCP, FRCPE, FCP

Department of Medicine \& Research Centre of Heart, Brain, Hormone and Healthy Aging,

*Department of Biochemistry and Genome Research Centre,

University of Hong Kong, Queen Mary Hospital, Hong Kong.

Address for correspondence: $\quad$ Dr. B.M.Y. Cheung

Department of Medicine, University of Hong Kong

Queen Mary Hospital, 102 Pokfulam Road, Hong Kong

Tel: (852) $28554768 \quad$ Fax: (852) 29049443

e-mail: mycheung@hkucc.hku.hk 


\section{Abstract:}

We studied single nucleotide polymorphisms (SNPs) and haplotypes in the urotensin-II (UTS2) and urotensin-II receptor gene (UTS2R) in Hong Kong Chinese (224 hypertensive and 306 normotensive unrelated subjects) and their relation to hypertension and the metabolic syndrome. For UTS2, the GGT haplotype (-605G, 143G, 3836T) was associated with higher plasma level of U-II and insulin, and higher homeostasis model assessment of insulin resistance index and $\beta$-cell function. For UTS2R, the AC haplotype (-11640A, -8515C) was associated with higher 2-hour plasma glucose after a 75-g oral glucose load. Therefore, U-II and its receptor may play a role in insulin resistance.

[100 words]

Key words: urotensin II, hypertension, insulin resistance, metabolic syndrome, single nucleotide polymorphism, haplotype 


\section{Introduction}

$\mathrm{U}-\mathrm{II}$ is the most potent vasoconstrictor known and is more potent than endothelin-1 (ET-1)

[3]. Human U-II is an 11 amino acid cyclic peptide and is derived from a precursor molecule, prepro-U-II [22,23]. The gene encoding the peptide, UTS2, is located at $1 \mathrm{p} 36$ and contains 5 exons. U-II acts through a G-protein-coupled receptor, the UT receptor [3]. The gene encoding the receptor, UTS2R, is located at $17 \mathrm{q} 25.3$ and is intronless [24].

U-II circulates in human plasma and its plasma level is elevated in renal failure [41], congestive heart failure [16,21,27,28], portal hypertension caused by liver cirrhosis [14] and diabetes mellitus [39]. We previously reported that plasma U-II level is raised in hypertensive patients compared to normotensive controls and is directly related to the systolic blood pressure [8]. On the other hand, the elevation in plasma U-II level in diabetic patients is independent of the level of blood glucose [39]. U-II inhibits insulin secretion in the rat pancreas [31]. In Type 2 diabetic patients, plasma and urinary U-II level is higher in those with renal dysfunction than those with normal renal function [40].

A single nucleotide polymorphism (SNP) in UTS2, 143G $>$ A (rs228648), is associated with susceptibility to type 2 diabetes in Han Chinese [36,48]. Another SNP, 3836C>T (rs2890565) is associated with increased insulin resistance and susceptibility to type 2 
diabetes in Japanese $[37,45]$. However, in previous studies of SNPs in UTS2 [36,37,45,48] there are no reports of SNPs in the promoter and haplotype analysis, and the influence of these SNPs on plasma U-II level has not been investigated. For the UT receptor, there is only one report of SNP study in Japanese population in which no SNP can be found in the coding region and the two SNPs in promoter region, $-7836 \mathrm{G}>\mathrm{A}$ and $-7814 \mathrm{C}>\mathrm{T}$ did not show any association with type 2 diabetes mellitus and related clinical parameter. Therefore, we hypothesized that U-II may play a role in the development of hypertension and metabolic syndrome, which is a cluster of metabolic abnormalities, associated with central (abdominal) obesity, raised fasting plasma glucose, raised blood pressure, raised triglycerides and reduced HDL cholesterol [2]. In this study, we sequenced the UTS2 promoter for novel SNPs, and investigated the association of haplotypes and SNPs in the UTS2 gene with hypertension and clinical parameters important in metabolic syndrome, such as insulin resistance, plasma glucose, plasma insulin, lipid profile and blood pressure, etc. We also investigated the association of two known SNPs in the UTSR2 gene promoter, -11640G $>$ A (rs7502620) and $-8515 \mathrm{~T}>\mathrm{C}$ (rs7211435) which has been documented in the HapMap database, with the clinical parameters.

\section{Subjects and Methods}




\subsection{Subjects}

The study protocol had been approved by the Institutional Review Board of the University of Hong Kong/Hospital Authority Hong Kong West Cluster. We studied 224 hypertensive patients and 306 normotensive controls with their informed consent. The subjects were all unrelated Hong Kong Chinese. Hypertensive subjects were recruited from the Hypertension Clinic of a teaching hospital. Hypertension was defined as systolic blood pressure $\geq 140 \mathrm{mmHg}$, or a diastolic blood pressure $\geq 90 \mathrm{mmHg}$ on at least 3 separate occasions. Patients on treatment who were previously diagnosed as hypertensive by the above criteria were also eligible. Patients with secondary hypertension (e.g. renal artery stenosis, coarctation, glomerulonephritis, pyelonephritis, phaeochromocytoma, Cushing's syndrome, Conn's syndrome) were excluded. Normotensive controls were recruited from a cohort of subjects previously randomly recruited from the general population $[9,15]$.

Physical examination (including measurement of height, weight, body fat, waist and hip circumference), urine analysis and ECG were performed and a full medical history (including past medical history, drug history, family history, smoking status, alcohol intake and exercise habit) was obtained. Bioelectrical impedance was measured as an estimate of percentage body fat (Tanita TBF-531, Tanita Corporation, Tokyo, Japan). Lipid profile, fasting glucose, insulin and 2-hour glucose after a 75-g oral glucose load were measured. Insulin resistance 
was assessed with the homeostasis model assessment of insulin resistance index (HOMA-IR), which is the product of the fasting plasma insulin (FPI) (mIU/L) and fasting plasma glucose (FPG) (mmol/L) divided by 22.5 [18]. Pancreatic $\beta$-cell function, estimated as HOMA- $\beta \%$, is given by $(20 \mathrm{xFP}) /(\mathrm{FPG}-3.5)$.

Subjects were studied in the morning after overnight fasting. The blood pressure of each patient was measured using a mercury sphygmomanometer by a trained nurse manually after the subject had been sitting and resting for at least 5 minutes. Blood pressure was measured three times at 5 minute intervals. The first blood pressure measurement was to familiarise the patient with the procedure and the sensation of the inflated cuff. The 2 subsequent systolic and phase $\mathrm{V}$ diastolic blood pressure readings were recorded to the nearest $2 \mathrm{mmHg}$. The mean of the 2 readings was used in data analysis.

After sitting or resting for at least 5 minutes, $20 \mathrm{ml}$ venous blood was taken from a forearm vein for a full blood count (haemoglobin, haematocrit, white blood count, differential white count and platelet count), renal and liver function tests (sodium, potassium, urea, creatinine, glucose, total bilirubin, total protein, albumin, ALT and alkaline phosphatase), plasma insulin and lipid profile. In 29 hypertensive subjects and 54 control subjects, $10 \mathrm{ml}$ venous blood was placed in a pre-chilled EDTA bottle and placed on ice immediately. In an adjacent room, 
the blood was immediately centrifuged at $4^{\circ} \mathrm{C}$ to obtain the buffy coat and the plasma was frozen at $-70^{\circ} \mathrm{C}$ until the time of assay. Plasma U-II was measured by radioimmunoassay as described previously [8].

\subsection{Genomic DNA Amplification and SNP identification}

Genomic DNA was extracted from the buffy coat using the QIAamp DNA Mini Kit (Qiagen, Hilden, Germany) according to the manufacturer's protocol. Candidate SNPs were selected from the dbSNP database and their locations are shown in Figure 1. Genomic sequence was obtained from GenBank (accession numbers NT021937 and NT010663). To sequence a 1,600-bp UTS2 promoter region, three primer sets were designed. PCR reactions were performed in 22-27 subjects using primers, U2P1 (5'-AGT GAC GCA GAG CAT AAG ATG A-3') and U2P2 (5'-CAC CAC ACC TGG TTA ATT GTT G-3') to amplify a 1019bp from +120 to -899, U2P3 (5'-CTG GGC AAC ATA GAG AAA CAC-3') and U2P4 (5'-CCT CCT GTC TCA ATT TTT TTC-3') to amplify a $627 \mathrm{bp}$ segment from -525 to -1151 , and U2P5 (5'-AGA CAA GAC ACA AAT CAC ACA G-3') and U2P6 (5'-AGT TTT GCT CTT GCC ACC C-3') to amplify a 534bp segment from -1109 to -1642 . The SNPs in the UTS2 promoter region were identified by direct sequencing using ABI 3730 DNA Analyzer (Applied Biosystems, Foster City, USA). 


\subsection{Genotyping}

High-throughput genotyping of the SNPs in UTS2 (except $-605 \mathrm{G}>\mathrm{A}$ and $-788 \mathrm{C}>\mathrm{T}$ ) and UTS2R were performed using the Sequenom MassARRAY system (Sequenom, San Diego, CA) which utilizes Matrix Assisted Laser Desorption Ionization-Time Of Flight (MALDI-TOF) technology.

Genotyping of $-605 \mathrm{G}>\mathrm{A}$ and the novel SNP, $-788 \mathrm{C}>\mathrm{T}$ in UTS2, were performed using FokI and MwoI (New England Biolabs, Beverly, MA) to generate restriction fragment length polymorphisms (RFLP). A 375bp fragment incorporating these 2 SNPs (-525 to -899) was amplified from genomic DNA using primers, U2P2 and U2P3. A single FokI site and 2 MwoI sites are present within this 375bp fragment (Figure 2). The $-605 \mathrm{G}>\mathrm{A}$ substitution eliminates the FokI site while $-788 \mathrm{C}>\mathrm{T}$ substitution eliminates one of the $2 \mathrm{MwoI}$ sites. The PCR product was digested with either FokI or MwoI for 4 hours at $37^{\circ} \mathrm{C}$ or $60^{\circ} \mathrm{C}$ respectively. The digested products were analyzed by gel electrophoresis in $10 \%$ polyacrylamide gels.

\subsection{Statistical analysis}

Data were analysed using a statistical software programme (SPSS for Windows, ver. 11.0, SPSS Inc., Chicago, USA). Genotype frequencies for each SNP were tested for Hardy-Weinberg equilibrium. As the distributions of fasting plasma insulin, HOMA-IR and 
HOMA- $\beta \%$ were skewed, these were expressed as geometric means with $95 \%$ confidence intervals (CIs). Comparison of clinical characteristics was performed using unpaired student's $t$ test or Mann-Whitney $U$ test for continuous variables, and Chi-square test for categorical variables. Stepwise multiple regression analysis was performed with HOMA-IR as the dependent variable. The predictor variables examined included sex, age, body mass index (BMI) and plasma U-II level. The programme Haploview (ver. 3.2) was used to assess linkage disequilibrium for all possible SNP pairs by determining $r^{2}$ [5]. Haplotypes were predicted using the programme PHASE (ver. 2.1.1), which implements a Bayesian method for estimating haplotypes from population genotype data $[7,33,34]$. For haplotype analysis, subjects who carried a particular haplotype with a probability $\geq 0.95$ were also included. Analysis of covariance (ANCOVA) was used for comparing the fasting plasma insulin, HOMA-IR, HOMA- $\beta \%$, plasma U-II level and 2-hour plasma glucose of groups with different haplotypes, with age, sex, BMI and HOMA-IR as covariates where indicated. A 2-tailed p-value less than 0.05 was considered statistically significant.

\section{Results}

\subsection{Baseline characteristics}

We studied 224 hypertensive subjects and 306 normotensive controls. Their baseline characteristics are shown in Table 1. There were as expected, significant differences in 
blood pressure, weight, BMI, percentage body fat, plasma cholesterol level, fasting plasma glucose, fasting plasma insulin, HOMA-IR, HOMA- $\beta \%$, plasma U-II level and the prevalence of diabetes mellitus and metabolic syndrome according to the NCEP ATP III guidelines [20]. Genotyping of the two SNPs $-11640 \mathrm{G}>\mathrm{A}$ and $-8515 \mathrm{~T}>\mathrm{C}$ in UTS2R were performed in only 174 normotensive controls and 114 hypertensive subjects.

\subsection{Plasma U-II level and HOMA-IR}

Plasma U-II level correlated with ln [HOMA-IR] $(r=0.242, \mathrm{p}=0.027)$. In stepwise multiple regression analysis, ln [HOMA-IR] was related to plasma U-II level $(\beta=0.23, p=0.020)$, sex $(\beta=0.30, p=0.005)$ and BMI $(\beta=0.47, p<0.001)$. These variables explain $25.8 \%$ of the variation in HOMA-IR $(\mathrm{p}<0.001)$.

\subsection{Identification of SNPs in UTS2 promoter by direct sequencing}

Five SNPs were identified in the promoter region of UTS2 by direct sequencing. A novel (C>T) SNP was found at position -788 which has not been reported before. The other SNPs $(-18 \mathrm{C}>\mathrm{T},-605 \mathrm{G}>\mathrm{A},-1263 \mathrm{C}>\mathrm{T}$ and $-1477 \mathrm{C}>\mathrm{T})$ have been reported in the dbSNP database previously and showed heterozygosity in our population. However, the minor allele frequencies of $-18 \mathrm{C}>\mathrm{T}$ and $-1477 \mathrm{C}>\mathrm{T}$ were less than $5 \%$ and therefore not further analysed. Two SNPs (-660C $>$ T and $-789 \mathrm{G}>$ A) previously identified in African Americans as described 
in the dbSNP database were homozygous in our sample.

\subsection{SNP genotyping}

The $-605 \mathrm{G}>\mathrm{A}$ and $-788 \mathrm{C}>\mathrm{T}$ variants were genotyped by FokI-RFLP (Figure 3a) and MwoI-RFLP (Figure 3b) respectively, while other SNPs in UTS2 (-1263C $>$ T, 143G $>$ A and $3836 \mathrm{C}>\mathrm{T})$ and $\operatorname{UTS} 2 R(-11640 \mathrm{G}>\mathrm{A}$ and $-8515 \mathrm{~T}>\mathrm{C})$ were genotyped using the Sequenom. The results are shown in Table 2. For each SNP, the observed genotype frequencies showed no significant deviation from Hardy-Weinberg equilibrium.

\subsection{Linkage disequilibrium}

In this study, $r^{2}$ was used to measure linkage disequilibrium as it is independent of allele frequency and appropriate for modest sample sizes [13,29]. The average $r^{2}$ value across the UTS2 gene was 0.18 . The SNPs, $-605 \mathrm{G}>\mathrm{A}$ and $143 \mathrm{G}>\mathrm{A}$ are in almost complete linkage disequilibrium $\left(r^{2}=0.99\right)$. For UTS2R, the 2 SNPs, $-11640 \mathrm{G}>\mathrm{A}$ and $-8515 \mathrm{~T}>\mathrm{C}$ are also in almost complete linkage disequilibrium $\left(r^{2}=0.99\right)$.

\subsection{Single variant analysis of UTS2}

Plasma U-II level was related to $3836 \mathrm{C}>\mathrm{T}$ (Table 3, $\mathrm{p}=0.006$ after adjusting for sex, age and BMI), especially among the normotensive subjects ( $p=0.002$ and after adjustment, $p=0.002)$. 
Plasma U-II level was not significantly related to $-1263 \mathrm{C}>\mathrm{T},-788 \mathrm{C}>\mathrm{T},-605 \mathrm{G}>\mathrm{A}$ or $143 \mathrm{G}>\mathrm{A}$ (Table 3).

The 3 SNPs, $-605 \mathrm{G}>\mathrm{A}, \quad 143 \mathrm{G}>\mathrm{A}$ and $3836 \mathrm{C}>\mathrm{T}$ were significantly associated with HOMA- $\beta \%$ (Table 4). $3836 \mathrm{C}>\mathrm{T}$ was also significantly associated with higher fasting plasma insulin and HOMA-IR. The associations remained significant after adjusting for sex, age and BMI ( $\mathrm{p}=0.024,0.038$ and 0.040 for plasma insulin, HOMA-IR and HOMA- $\beta \%$ respectively). However, none of the SNPs studied was associated with hypertension (Table 2), waist circumference, plasma triglyceride, plasma cholesterol, plasma HDL cholesterol, fasting plasma glucose or blood pressure $(\mathrm{p}>0.05)$.

\subsection{Haplotype analysis of UTS2}

The most common five-locus haplotypes, comprising the five nucleotide variants at positions $-1263,-788,-605,143$ and 3836, and their frequencies were CCGGC (0.31), CCGGT (0.30), CCAAC (0.24), CTAAC (0.09), TCGGC (0.03) and CTAAT (0.02). As the 3 most common five-locus haplotype differs only at the three SNPs, $-605 \mathrm{G}>\mathrm{A}, 143 \mathrm{G}>\mathrm{A}$ and $3836 \mathrm{C}>\mathrm{T}$ and only these three SNPs showed some associations with clinical parameters, three-locus haplotypes made up of $-605 \mathrm{G}>\mathrm{A}, 143 \mathrm{G}>\mathrm{A}$ and $3836 \mathrm{C}>\mathrm{T}$ were constructed for further analysis. The most common three-locus haplotypes and their frequencies were GGC (0.35), 
AAC (0.33), GGT (0.30) and AAT (0.02). Carriers of GGT haplotype had higher fasting plasma insulin, HOMA-IR and HOMA- $\beta \%$ (Table 4). The association remained significant after adjusting for age, sex and BMI ( $\mathrm{p}=0.029,0.045$ and 0.049 respectively). Moreover, the fasting plasma insulin, HOMA-IR and HOMA- $\beta \%$ increased with number of GGT haplotype $(\mathrm{p}=0.017,0.032$ and 0.021$)$. Among non-diabetic normotensive subjects, the GGT haplotype was only associated with higher fasting plasma insulin and HOMA-IR, but not HOMA- $\beta \%$ ( $p=0.038,0.026$ and 0.274 respectively and after adjusting for age, sex and BMI, $\mathrm{p}=0.037,0.024$ and 0.309 respectively). However, none of the haplotypes studied was associated with hypertension, waist circumference, plasma triglyceride, plasma cholesterol, plasma HDL cholesterol, fasting plasma glucose or blood pressure $(\mathrm{p}>0.05)$.

Carriers of GGT haplotypes had higher plasma U-II level (Table 3, p=0.016 after adjusting for sex, age and BMI), especially among the normotensive subjects ( $p=0.006$ and after adjustment, $\mathrm{p}=0.007)$.

\subsection{Single variant and haplotype analysis of UTS2R}

Both the two SNPs, $-11640 \mathrm{G}>\mathrm{A}$ and $-8515 \mathrm{~T}>\mathrm{C}$ were significantly associated with higher 2-hour plasma glucose after a 75-g oral glucose load (Table 5). The associations remained significant after adjusting for sex, age and BMI $(\mathrm{p}=0.024$ for both $-11640 \mathrm{G}>\mathrm{A}$ and 
-8515T $>$ C). The most common 2-locus haplotypes, comprising nucleotide variants at positions -11640 and -8515 , and their frequencies were GT (0.70) and $\mathrm{AC}(0.30)$. The AC haplotype showed similar results as the corresponding single variant (Table 5). The association of $\mathrm{AC}$ haplotype with 2-hour plasma glucose remained significant after adjusting for.sex, age, BMI and HOMA-IR ( $\mathrm{p}=0.020)$ and is more significant among the non-diabetic normotensive subjects ( $\mathrm{p}=0.001$ and after adjustment, $\mathrm{p}=0.016$ ). However, none of the SNPs and haplotypes studied was associated with hypertension, waist circumference, plasma triglyceride, plasma HDL cholesterol, blood pressure, fasting plasma glucose, fasting plasma insulin, HOMA-IR and HOMA- $\beta \%$, $(\mathrm{p}>0.05)$.

\section{Discussion}

The most important findings of this study were the associations of haplotypes and SNPs in the UTS2 gene with plasma U-II level, insulin resistance and pancreatic $\beta$-cell function and that in UTS2R gene with 2-hour plasma glucose. We previously reported that plasma U-II level is raised in hypertensive patients compared to normotensive controls and is directly related to the systolic blood pressure [8]. Hypertension and insulin resistance are commonly found together in overweight persons as components of the metabolic syndrome $[20,26]$. In our local population, overweight and insulin resistance are important determinants of blood pressure [38]. Plasma insulin level and blood pressure are correlated in untreated patients 
with essential hypertension but not in those with secondary hypertension [32]. Insulin resistance and hyperinsulinemia can raise the blood pressure by a variety of mechanisms including activation of the renin-angiotensin-aldosterone and the sympathetic nervous systems, sodium retention, volume expansion, renal damage, atherosclerosis and oxidative stress [12]. Impaired insulin signalling in the insulin-resistant state contributes to vasoconstriction.

Previously, $143 \mathrm{G}>\mathrm{A}$ (T21M) polymorphism was found to be associated with diabetes mellitus in northern Chinese [36,48]. In Japanese subjects, 3836C $>\mathrm{T}$ (S89N) but not $143 \mathrm{G}>\mathrm{A}$, was reported to be significantly associated with type 2 diabetes, increased plasma insulin and higher HOMA-IR [37,45]. Our results on 3836C $>\mathrm{T}$ is consistent with that of Japanese study, showing the association of this polymorphism with insulin resistance.

The region $1 \mathrm{p} 36$ in human chromosome 1 contains the susceptible locus for type 2 diabetes in Chinese and Japanese [11,19]. The exact disease-containing gene remains to be identified. The UTS2 gene is at $1 \mathrm{p} 36$, raising the possibility that it may be one of the genes causing the metabolic syndrome. Local expressions of both U-II and UT receptor have been demonstrated in human pancreas $[3,10,35]$. In perfused rat pancreas, glucose-induced insulin release can be inhibited by infusion of 10nM and 100nM U-II while arginine-induced 
insulin release can be inhibited by infusion of 100nM [31]. This inhibition is not due to the vasoconstriction action of U-II but its activation of UT receptors in pancreatic $\beta$ cells and does not affect basal insulin release [30]. In this study, the associations of SNPs and haplotype in UT receptor with 2-hour plasma glucose level suggest a role of UT receptor in the development of impaired glucose tolerance which is a precursor to diabetes mellitus. The AC haplotype may increase the receptor sensitivity, density or expression, thus enhancing the inhibitory effect of U-II on insulin secretion in response to glucose load and resulting in a higher 2-hour plasma glucose level. This new finding further supports a role of U-II and its receptor in the regulation of insulin secretion and glucose metabolism.

However, early type 2 diabetes is characterised by hyperinsulinaemia rather than impairment in insulin production. Interestingly, we found that the U-II haplotype $-605 \mathrm{G} \backslash 143 \mathrm{G} \backslash 3836 \mathrm{~T}$ was significantly associated with higher plasma urotensin level, plasma insulin level, insulin resistance and $\beta$-cell function. In non-diabetic subjects, insulin secretion normally increases as a compensatory adaptation under the condition of insulin resistance [43]. The mechanism whereby this haplotype in U-II can cause insulin resistance remains speculative at present. However, it has been demonstrated that U-II can increase the releases of adrenocorticotropic hormone $(\mathrm{ACTH})$ and epinephrine through sympathoadrenal and pituitary-adrenal pathways [42]. The increase in ACTH may then contribute to an increase in insulin secretion. 
Moreover, insulin has vascular effects in addition to its metabolic effects; it induces endothelial-nitric-oxide-dependent vasodilatation as well as glucose uptake into peripheral tissues [4]. It is possible that U-II impairs both of these actions like endothelin-1 [46].

In this study, we found that the U-II haplotype $-605 \mathrm{G} / 143 \mathrm{G} / 3836 \mathrm{~T}$ was associated with higher plasma U-II level. In fact, 3836C $>\mathrm{T}$ was responsible for the association. This nucleotide transition in codon 266 of UTS2 is associated with a change from serine to asparagine at amino acid position 89. It is not known if this amino acid substitution is associated with an alteration in transcription, translation or secretion, and if there is alteration in degradation or receptor binding. Alternatively, there might be alteration in immunoreactivity. Further studies are needed to investigate this very common variant.

Although U-II is a highly potent vasoconstrictor in vitro, its infusion in man does not produce such a response [1,47]. We and others postulate that the net effect of U-II on vascular tone is determined by the balance between its direct vasoconstrictor effect and its indirect vasodilatory effect mediated by endothelium derived relaxing factors such as nitric oxide $[6,17,23]$. In diseases characterised by endothelial dysfunction, the vasoconstriction and the mitogenic effect on vascular smooth muscle may predominate. In this regard, we have observed that tumour necrosis factor-alpha (TNF- $\alpha$ ) upregulates the expression of U-II and 
the UT receptor in endothelial cells in vitro [unpublished observations]. There is increased secretion of TNF- $\alpha$ and other inflammatory cytokines in the whole spectrum of cardiovascular disease and cardiovascular risk factors, including the metabolic syndrome $[25,44]$. U-II may therefore have a role in the pathogenesis of cardiovascular diseases and complications.

Genetic association studies are prone to false positives when multiple SNPs are tested in large sample sizes. Therefore, we have focussed on haplotypes made up of common alleles and large effect sizes. The population in Hong Kong is $95 \%$ Chinese, so population stratification is unlikely to be serious. Nevertheless, our results need to be confirmed in further studies in a different setting and population.

In conclusion, our study showed that haplotypes and SNPs in the UTS2 and UTS2R genes in Hong Kong Chinese were associated with plasma U-II level, pancreatic $\beta$-cell function, insulin resistance and 2-hour plasma glucose although they were not associated with hypertension. These suggest that U-II and its receptor may play a role in the development of insulin resistance, hyperinsulinemia and impaired glucose tolerance, components of metabolic syndrome.

\section{Acknowledgements}


Analysis using the Sequenom genotyping system was performed with the help of Dr William

Mak and Miss Phoebe Ng of the Genome Research Centre, University of Hong Kong. BMY Cheung received a University of Hong Kong Committee on Research and Conference Grant to study urotensin II. BMY Cheung is a member of the Institute of Cardiovascular Science and Medicine.

\section{Conflict of interest}

None 


\section{References}

1. Affolter JT, Newby DE, Wilkinson IB, Winter MJ, Balment RJ, Webb DJ. No effect on central or peripheral blood pressure of systemic urotensin II infusion in humans. Br J Clin Pharmacol 2002;54:617-21.

2. Alberti KG, Zimmet P, Shaw J, IDF Epidemiology Task Force Consensus Group. The metabolic syndrome--a new worldwide definition. Lancet 2005;366:1059-62.

3. Ames RS, Sarau HM, Chambers JK, Willette RN, Aiyar NV, Romanic AM, Louden CS, Foley JJ, Sauermelch CF, Coatney RW, et al. Human urotensin II is a potent vasoconstrictor and agonist for the orphan receptor GPR14. Nature 1999;401:282-6.

4. Baron AD. Insulin resistance and vascular function. J Diabetes Complications 2002;16:92-102.

5. Barrett JC, Fry B, Maller J, Daly MJ. Haploview: analysis and visualization of LD and haplotype maps. Bioinformatics 2005;21:263-5.

6. Bottrill FE, Douglas SA, Hiley CR, White R. Human urotensin-II is an endothelium-dependent vasodilator in rat small arteries. $\mathrm{Br} \mathrm{J}$ Pharmacol 2000;130:1865-70.

7. Brand-Herrmann SM, Kopke K, Reichenberger F, Schmidt-Petersen K, Reineke T, Paul M, Zidek W, Brand E. Angiotensinogen promoter haplotypes are associated with blood pressure in untreated hypertensives. J Hypertens 2004;22:1289-97. 
8. Cheung BM, Leung R, Man YB, Wong LY. Plasma concentration of urotensin II is raised in hypertension. J Hypertens 2004;22:341-4.

9. Cheung BMY, Lam TH, Lam KSL, Tam SCF, Wat NMS, Man YB, Cheng CH, Kumana CR, Lau CP. The Hong Kong Cardiovascular Risk Factor Prevalence Survey cohort results at 7 years. J Hypertens 2004;22:S268-9.

10. Coulouarn Y, Lihrmann I, Jegou S, Anouar Y, Tostivint H, Beauvillain JC, Conlon JM, Bern HA, Vaudry H. Cloning of the cDNA encoding the urotensin II precursor in frog and human reveals intense expression of the urotensin II gene in motoneurons of the spinal cord. Proc Natl Acad Sci U S A 1998;95:15803-8.

11. Du W, Sun H, Wang H, Qiang B, Shen Y, Yao Z, Gu J, Xiong M, Huang W, Chen Z, et al. Confirmation of susceptibility gene loci on chromosome 1 in northern China Han families with type 2 diabetes. Chin Med J 2001;114:876-8.

12. El-Atat FA, Stas SN, McFarlane SI, Sowers JR. The relationship between hyperinsulinemia, hypertension and progressive renal disease. J Am Soc Nephrol 2004;15:2816-27.

13. Hill WG, Weir BS. Maximum-likelihood estimation of gene location by linkage disequilibrium. Am J Hum Genet 1994;54:705-14. 
14. Heller J, Schepke M, Neef M, Woitas R, Rabe C, Sauerbruch T. Increased urotensin II plasma levels in patients with cirrhosis and portal hypertension. J Hepatol 2002;37:767-72.

15. Janus ED, Wat NMS, Lam KSL, Siu STS, Liu LJ, Lam TH and for the Hong Kong Cardiovascular Risk Factor Steering Committee. The prevalence of diabetes, association with cardiovascular risk factors and implications of diagnostic criteria (ADA 1997 and WHO 1998) in a 1996 community-based population study in Hong Kong Chinese. Diabet Med 2000;17:741-5.

16. Lapp H, Boerrigter G, Costello-Boerrigter LC, Jaekel K, Scheffold T, Krakau I, Schramm M, Guelker H, Stasch JP. Elevated plasma human urotensin-II-like immunoreactivity in ischemic cardiomyopathy. Int J Cardiol 2004;94:93-7.

17. Lim M, Honisett S, Sparkes CD, Komesaroff P, Kompa A, Krum H. Differential effect of urotensin II on vascular tone in normal subjects and patients with chronic heart failure. Circulation 2004;109:1212-4.

18. Matthews DR, Hosker JP, Rudenski AS, Naylor BA, Treacher DF, Turner RC. Homeostasis model assessment: insulin resistance and ß-cell function from fasting glucose and insulin concentrations in man. Diabetologia 1985;28:412-9.

19. Mori Y, Otabe S, Dina C, Yasuda K, Populaire C, Lecoeur C, Vatin V, Durand E, Hara K, Okada T, et al. Genome-wide search for type 2 diabetes in Japanese affected sib-pairs 
confirms susceptibility genes on $3 \mathrm{q}, 15 \mathrm{q}$, and $20 \mathrm{q}$ and identifies two new candidate Loci on $7 \mathrm{p}$ and 11p. Diabetes 2002;51:1247-55.

20. National Cholesterol Education Program. Executive summary of the third report of the National Cholesterol Education Program (NCEP) expert panel on detection, evaluation, and treatment of high blood cholesterol in adults (Adult Treatment Panel III). JAMA 2001;285:2486-97.

21. Ng LL, Loke I, O'Brien RJ, Squire IB, Davies JE. Plasma urotensin in human systolic heart failure. Circulation 2002;106:2877-80.

22. Ong KL, Cheung BMY. Urotensin II and the circulatory system. Hong Kong J Nephrol $2005 ; 7: 9-13$.

23. Ong KL, Lam KSL, Cheung BMY. Urotensin II: its function in health and its role in disease. Cardiovasc Drugs Ther 2005;19:65-75.

24. Protopopov A, Kashuba V, Podowski R, Gizatullin R, Sonnhammer E, Wahlestedt C, Zabarovsky ER. Assignment of the GPR14 gene coding for the G-protein-coupled receptor 14 to human chromosome $17 \mathrm{q} 25.3$ by fluorescent in situ hybridization. Cytogenet Cell Genet 2000;88:312-3.

25. Rajala MW, Scherer PE. The adipocyte--at the crossroads of energy homeostasis, inflammation, and atherosclerosis. Endocrinology 2003;144:3765-73.

26. Reaven GM. Role of insulin resistance in human disease. Diabetes 1988;37:1595-607. 
27. Richards AM, Nicholls MG, Lainchbury JG, Fisher S, Yandle TG Plasma urotensin II in heart failure. Lancet 2002;360:545-6.

28. Russell FD, Meyers D, Galbraith AJ, Bett N, Toth I, Kearns P, Molenaar P. Elevated plasma levels of human urotensin-II immunoreactivity in congestive heart failure. Am J Physiol Heart Circ Physiol 2003;285:H1576-81.

29. Shifman S, Kuypers J, Kokoris M, Yakir B, Darvasi A. Linkage disequilibrium patterns of the human genome across populations. Hum Mol Genet 2003;12:771-6.

30. Silvestre RA, Egido EM, Hernandez R, Leprince J, Chatenet D, Tollemer H, Chartrel N, Vaudry H, Marco J. Urotensin-II is present in pancreatic extracts and inhibits insulin release in the perfused rat pancreas. Eur J Endocrinol 2004;151:803-9.

31. Silvestre RA, Rodriguez-Gallardo J, Egido EM, Marco J. Inhibition of insulin release by urotensin II--a study on the perfused rat pancreas. Horm Metab Res 2001;33:379-81.

32. Sowers JR. Insulin resistance and hypertension. Am J Physiol Heart Circ Physiol 2004;286:H1597-602.

33. Stephens M, Donelly P. A comparison of Bayesian methods for haplotype reconstruction from population genotype data. Am J Hum Genet 2003;73:1162-9.

34. Stephens M, Smith N, Donelly P. A new statistical method for haplotype reconstruction from population data. Am J Hum Genet 2001;68:978-89. 
35. Sugo T, Murakami Y, Shimomura Y, Harada M, Abe M, Ishibashi Y, Kitada C, Miyajima N, Suzuki N, Mori M, et al. Identification of urotensin II-related peptide as the urotensin II-immunoreactive molecule in the rat brain. Biochem Biophys Res Commun 2003;310:860-8.

36. Sun HX, Du WN, Zuo J, Wu GD, Shi GB, Shen Y, Qiang BQ, Yao ZJ, Hang JM, Wang $\mathrm{H}$, et al. The association of two single nucleotide polymorphisms in PRKCZ and UTS2 respectively with type 2 diabetes in Han people of northern China. Zhongguo Yi Xue Ke Xue Yuan Xue Bao 2002;24:223-7.

37. Suzuki S, Wenyi Z, Hirai M, Hinokio Y, Suzuki C, Yamada T, Yoshizumi S, Suzuki M, Tanizawa Y, Matsutani A, et al. Genetic variations at urotensin II and urotensin II receptor genes and risk of type 2 diabetes mellitus in Japanese. Peptides 2004;25:1803-8.

38. Thomas GN, Critchley JA, Tomlinson B, Anderson PJ, Lee ZS, Chan JC. Obesity, independent of insulin resistance, is a major determinant of blood pressure in normoglycemic Hong Kong Chinese. Metabolism 2000;49:1523-8.

39. Totsune K, Takahashi K, Arihara Z, Sone M, Ito S, Murakami O. Increased plasma urotensin II levels in patients with diabetes mellitus. Clinical Science 2003;104:1-5.

40. Totsune K, Takahashi K, Arihara Z, Sone M, Murakami O, Ito S, Kikuya M, Ohkubo T, Hashimoto J, Imai Y. Elevated plasma levels of immunoreactive urotensin II and its 
increased urinary excretion in patients with Type 2 diabetes mellitus: association with progress of diabetic nephropathy. Peptides 2004;25:1809-14.

41. Totsune K, Takahashi K, Arihara Z, Sone M, Satoh F, Ito S, Kimura Y, Sasano H, Murakami O Role of urotensin II in patients on dialysis. Lancet 2001;358:810-1.

42. Watson AM, Lambert GW, Smith KJ, May CN. Urotensin II acts centrally to increase epinephrine and $\mathrm{ACTH}$ release and cause potent inotropic and chronotropic actions. Hypertension 2003;42:373-9.

43. Weir GC, Bonner-Weir S. Five stages of evolving beta-cell dysfunction during progression to diabetes. Diabetes 2004;53:S16-21.

44. Wellen KE, Hotamisligil GS. Obesity-induced inflammatory changes in adipose tissue. J Clin Invest 2003;112:1785-8.

45. Wenyi Z, Suzuki S, Hirai M, Hinokio Y, Tanizawa Y, Matsutani A, Satoh J, Oka Y. Role of urotensin II gene in genetic susceptibility to type 2 diabetes mellitus in Japanese subjects. Diabetologia 2003;46:972-6.

46. Wilkes JJ, Hevener A, Olefsky J. Chronic endothelin-1 treatment leads to insulin resistance in vivo. Diabetes 2003;52:1904-9.

47. Wilkinson IB, Affolter JT, de Haas SL, Pellegrini MP, Boyd J, Winter MJ, Balment RJ, Webb DJ. High plasma concentrations of human urotensin II do not alter local or systemic hemodynamics in man. Cardiovasc Res 2002;53:341-7. 
48. Zhu F, Ji L, Luo B. The role of urotensin II gene in the genetic susceptibility to type 2 diabetes in Chinese population. Zhonghua Yi Xue Za Zhi 2002;82:1473-5. 
Table 1 Baseline characteristics of the 530 subjects

Table 2 Allelic frequencies of SNPs in normotensive and hypertensive subjects

Table 3 Association between the SNPs and haplotypes of UTS2 gene and plasma urotensin II level

Table 4 Effect of the SNPs, $-605 \mathrm{G}>\mathrm{A}, 143 \mathrm{G}>\mathrm{A}$ and $3836 \mathrm{C}>\mathrm{T}$ in UTS2 gene and the corresponding haplotypes on fasting plasma insulin, HOMA-IR and HOMA- $\beta \%$

Table 5 Effect of the SNPs, $-11640 \mathrm{G}>\mathrm{A}$ and $-8515 \mathrm{~T}>\mathrm{C}$ in UTS2R gene and the cooresponding haplotypes on 2 hour plasma glucose level after oral glucose tolerance test and plasma cholesterol level

Figure 1 A schematic diagram of the map of (a) UTS2 gene and (b) UTS2R gene showing the locations of the SNPs studied. Exons and intron are represented by grey boxes and thin lines respectively with their sizes indicated.

Figure 2 Sequence of part of the UTS2 promoter. The nucleotides underlined with solid lines are the annealing sites of the primers, U2P3 and U2P2 for RFLP and those with dash lines are the restriction enzyme recognition sites. The locations of the two SNPs are indicated by the $\operatorname{symbol}(\bullet)$.

Figure 3 RFLP genotyping. (a) The $-605 \mathrm{G}>$ A substitution eliminates a FokI site, producing a single fragment (375bp) instead of 2 smaller fragments (98 and $281 \mathrm{bp}$ ). (b) The $-788 \mathrm{C}>\mathrm{T}$ substitution eliminates one of two MwoI sites, producing 2 fragments (134 and 244bp) 
instead of 3 fragments (19, 118 and 244bp). 
Table 1

\begin{tabular}{lccc}
\hline & Normotensive & Hypertensive & p-value \\
\hline $\mathrm{N}$ & 306 & 224 & - \\
Sex (male:female) & $155: 151$ & $123: 101$ & 0.332 \\
Age (yrs) & $52.8 \pm 11.4$ & $57.2 \pm 11.0$ & $<0.001$ \\
Regular alcohol consumption (\%) & 13.5 & 10.9 & 0.360 \\
Systolic pressure (mmHg) & $116.2 \pm 11.9$ & $144.3 \pm 18.4$ & $<0.001$ \\
Diastolic pressure (mmHg) & $72.8 \pm 7.7$ & $86.5 \pm 11.0$ & $<0.001$ \\
Weight (kg) & $59.8 \pm 10.0$ & $64.2 \pm 10.9$ & $<0.001$ \\
BMI (kg/m ${ }^{2}$ ) & $23.2 \pm 3.0$ & $25.0 \pm 3.3$ & $<0.001$ \\
Body fat (\%) & $27.2 \pm 7.2$ & $30.3 \pm 7.5$ & $<0.001$ \\
Waist circumference (cm) & $78.2 \pm 8.9$ & $83.8 \pm 9.3$ & $<0.001$ \\
Plasma cholesterol (mmol/l) & $5.2 \pm 0.8$ & $5.4 \pm 0.9$ & 0.001 \\
Plasma HDL cholesterol & $1.5 \pm 0.4$ & $1.4 \pm 0.4$ & 0.009 \\
(mmol/L) & & & $<0.001$ \\
Plasma triglyceride (mmol/L) & $1.2 \pm 0.7$ & $1.6 \pm 1.1$ & $<0.0001$ \\
Fasting plasma glucose (mmol/L) & $5.1 \pm 0.7$ & $5.4 \pm 1.1$ & 0.003 \\
2-hour plasma glucose (mmol/L) & $6.7 \pm 1.9$ & $7.4 \pm 1.9$ & $<0.001$ \\
Fasting plasma insulin (mIU/L) & $6.6(6.3-7.0)$ & $8.3(7.7-8.9)$ & $<0.001$ \\
HOMA-IR & $1.5(1.4-1.6)$ & $2.0(1.8-2.1)$ & $<0.001$ \\
HOMA- $\beta \%$ & $87.1(81.8-92.9)$ & $97.0(89.5-105.2)$ & 0.039 \\
Diabetes mellitus (\%) & 2.0 & 5.4 & 0.033 \\
Metabolic syndrome (\%) & 7.2 & 24.4 & $<0.001$ \\
Antihypertensive treatment (\%) & - & 45.1 & - \\
\hline & & & \\
\hline
\end{tabular}

Data are expressed as mean \pm SD or geometric mean with $95 \%$ confidence interval unless otherwise noted. 
Table 2

\begin{tabular}{|c|c|c|c|c|c|c|}
\hline \multirow[t]{2}{*}{ SNP } & \multirow[t]{2}{*}{ Allele } & \multirow[t]{2}{*}{ Normotensive } & \multirow[t]{2}{*}{ Hypertensive } & \multicolumn{2}{|c|}{$\begin{array}{c}\text { Hardy-Weinberg } \\
\text { equilibrium }\end{array}$} & \multirow[t]{2}{*}{$\mathrm{p}$-value } \\
\hline & & & & $\chi^{2}$ & $\mathrm{p}$-value & \\
\hline \multicolumn{7}{|l|}{ UTS2: } \\
\hline$-1263 \mathrm{C}>\mathrm{T}$ & $\mathrm{C}$ & $95.5 \%$ & $97.5 \%$ & 1.01 & 0.31 & 0.090 \\
\hline (rs7367534) & $\mathrm{T}$ & $4.5 \%$ & $2.5 \%$ & & & \\
\hline$-788 \mathrm{C}>\mathrm{T}$ & $\mathrm{C}$ & $89.7 \%$ & $90.4 \%$ & 0.39 & 0.53 & 0.709 \\
\hline (Novel SNP) & $\mathrm{T}$ & $10.3 \%$ & $9.6 \%$ & & & \\
\hline$-605 \mathrm{G}>\mathrm{A}$ & G & $64.4 \%$ & $67.4 \%$ & 2.09 & 0.14 & 0.305 \\
\hline (rs228647) & A & $35.6 \%$ & $32.6 \%$ & & & \\
\hline $143 \mathrm{G}>\mathrm{A}$ & G & $64.4 \%$ & $67.2 \%$ & 2.28 & 0.12 & 0.342 \\
\hline$(\mathrm{rs} 228648)$ & A & $35.6 \%$ & $32.8 \%$ & & & \\
\hline $3836 \mathrm{C}>\mathrm{T}$ & $\mathrm{C}$ & $69.1 \%$ & $67.9 \%$ & 1.14 & 0.28 & 0.662 \\
\hline (rs2890565) & $\mathrm{T}$ & $30.9 \%$ & $32.1 \%$ & & & \\
\hline \multicolumn{7}{|l|}{ UTS2R: } \\
\hline$-11640 \mathrm{G}>\mathrm{A}$ & G & $71.3 \%$ & $67.5 \%$ & 0.41 & 0.52 & 0.079 \\
\hline (rs7502620) & A & $28.7 \%$ & $32.5 \%$ & & & \\
\hline$-8515 \mathrm{~T}>\mathrm{C}$ & $\mathrm{T}$ & $71.3 \%$ & $68.0 \%$ & 0.70 & 0.40 & 0.401 \\
\hline (rs7211435) & $\mathrm{C}$ & $28.7 \%$ & $32.0 \%$ & & & \\
\hline
\end{tabular}


Table 3

\begin{tabular}{|c|c|c|c|c|}
\hline $\begin{array}{l}\text { Variants / } \\
\text { haplotypes }\end{array}$ & & $\mathrm{N}$ & $\begin{array}{l}\text { Plasma urotensin II } \\
(\mathrm{pmol} / \mathrm{L})\end{array}$ & $\mathrm{p}$-value \\
\hline \multirow[t]{2}{*}{$-1263 C>T$} & $\mathrm{CC}$ & 77 & $8.18 \pm 0.68$ & 0.903 \\
\hline & $\mathrm{CT}+\mathrm{TT}$ & 6 & $8.49 \pm 2.36$ & \\
\hline \multirow[t]{2}{*}{$-788 \mathrm{C}>\mathrm{T}$} & $\mathrm{CC}$ & 68 & $8.43 \pm 0.73$ & 0.469 \\
\hline & $\mathrm{CT}+\mathrm{TT}$ & 15 & $7.19 \pm 1.46$ & \\
\hline \multirow[t]{2}{*}{$-605 \mathrm{G}>A$} & GG & 33 & $9.14 \pm 1.24$ & 0.249 \\
\hline & $\mathrm{GA}+\mathrm{AA}$ & 50 & $7.59 \pm 0.71$ & \\
\hline \multirow[t]{2}{*}{$143 \mathrm{G}>\mathrm{A}$} & GG & 33 & $9.14 \pm 1.24$ & 0.249 \\
\hline & $\mathrm{GA}+\mathrm{AA}$ & 50 & $7.59 \pm 0.71$ & \\
\hline \multirow[t]{2}{*}{$3836 \mathrm{C}>\mathrm{T}$} & $\mathrm{CC}$ & 45 & $6.63 \pm 0.73$ & 0.008 \\
\hline & $\mathrm{CT}+\mathrm{TT}$ & 38 & $10.07 \pm 1.07$ & \\
\hline \multirow[t]{2}{*}{ GGC } & Non-carrier & 34 & $9.53 \pm 1.04$ & 0.091 \\
\hline & carrier & 49 & $7.28 \pm 0.82$ & \\
\hline \multirow[t]{2}{*}{ GGT } & Non-carrier & 46 & $6.84 \pm 0.75$ & 0.020 \\
\hline & carrier & 37 & $9.89 \pm 1.09$ & \\
\hline \multirow[t]{2}{*}{ AAC } & Non-carrier & 33 & $9.14 \pm 1.24$ & 0.249 \\
\hline & carrier & 50 & $7.59 \pm 0.71$ & \\
\hline
\end{tabular}

Data are expressed as mean \pm SEM 
Table 4

\begin{tabular}{|c|c|c|c|c|c|}
\hline $\begin{array}{l}\text { Variants / } \\
\text { haplotypes }\end{array}$ & & $\mathrm{N}$ & plasma insulin (mIU/L) & HOMA-IR & HOMА- $\beta \%$ \\
\hline \multirow[t]{2}{*}{$-605 \mathrm{G}>\mathrm{A}$} & GG & 221 & $7.67(7.14-8.24)$ & $1.75(1.62-1.89)$ & $98.93(91.29-107.22)$ \\
\hline & $\mathrm{GA}+\mathrm{AA}$ & 309 & $7.05(6.63-7.49)$ & $1.64(1.53-1.75)$ & $86.02(80.70-91.69)^{* * *}$ \\
\hline \multirow[t]{2}{*}{$143 \mathrm{G}>\mathrm{A}$} & GG & 220 & $7.62(7.10-8.19)$ & $1.74(1.61-1.88)$ & $98.54(90.92-106.81)$ \\
\hline & $\mathrm{GA}+\mathrm{AA}$ & 310 & $7.08(6.66-7.52)$ & $1.64(1.54-1.76)$ & $86.30(80.96-92.00)^{* *}$ \\
\hline \multirow[t]{3}{*}{$3836 \mathrm{C}>\mathrm{T}$} & $\mathrm{CC}$ & 244 & $6.80(6.33-7.30)$ & $1.57(1.45-1.69)$ & $84.92(78.73-91.60)$ \\
\hline & $\mathrm{CT}+\mathrm{TT}$ & 286 & $7.75(7.30-8.24)^{* * *}$ & 1.79 & $96.90(90.64-103.59)^{* *}$ \\
\hline & & & & $(1.67-1.91)^{* * *}$ & \\
\hline \multirow[t]{2}{*}{ GGC } & Non-carrier & 216 & $7.31(6.81-7.84)$ & $1.69(1.57-1.82)$ & $90.44(83.70-97.72)$ \\
\hline & carrier & 312 & $7.26(6.83-7.73)$ & $1.67(1.56-1.79)$ & $91.44(85.54-97.74)$ \\
\hline \multirow[t]{2}{*}{ GGT } & Non-carrier & 249 & $6.79(6.33-7.29)$ & $1.56(1.45-1.69)$ & $84.92(78.80-91.51)$ \\
\hline & carrier & 279 & $7.75(7.29-8.23)^{* * *}$ & $1.79(1.67-1.91)^{* *}$ & $96.85(90.51-103.64)^{* *}$ \\
\hline \multirow[t]{2}{*}{$\mathrm{AAC}$} & Non-carrier & 228 & $7.58(7.06-8.14)$ & $1.74(1.61-1.87)$ & $96.97(89.40-105.18)$ \\
\hline & carrier & 301 & $7.06(6.64-7.51)$ & $1.64(1.53-1.75)$ & $86.79(81.44-92.49)^{*}$ \\
\hline
\end{tabular}

Data are expressed as geometric mean $(95 \% \mathrm{CI})$

$* \mathrm{p}=0.03, * * \mathrm{p}=0.01, * * * \mathrm{p}<0.01$ compared to non-carriers of minor allele of the particular single variant or non-carrier of the particular haplotype. 


\section{Table 5}

\begin{tabular}{llll}
\hline Variants / & & \multicolumn{2}{l}{2 hour plasma glucose $(\mathrm{mmol} / \mathrm{L})$} \\
haplotypes & & $\mathrm{N}$ & Mean $\pm \mathrm{SE}$ \\
\hline$-11640 \mathrm{G}>\mathrm{A}$ & $\mathrm{GG}$ & 138 & $6.53 \pm 0.14^{*}$ \\
& $\mathrm{GA}+\mathrm{AA}$ & 150 & $7.04 \pm 0.14^{*}$ \\
& & & \\
$-8515 \mathrm{~T}>\mathrm{C}$ & $\mathrm{TT}$ & 138 & $6.53 \pm 0.14^{*}$ \\
& $\mathrm{TC}+\mathrm{CC}$ & 150 & $7.04 \pm 0.14^{*}$ \\
& & & \\
$\mathrm{GT}$ & Non-carrier & 24 & $6.80 \pm 0.30$ \\
& carrier & 264 & $6.79 \pm 0.11$ \\
& & & \\
AC & Non-carrier & 138 & $6.53 \pm 0.14^{*}$ \\
& carrier & 150 & $7.04 \pm 0.14^{*}$ \\
\hline
\end{tabular}

${ }^{*} \mathrm{p}=0.01$ compared to non-carriers of minor allele of the particular single variant or non-carrier of the particular haplotype. 
Figure 1

(a)

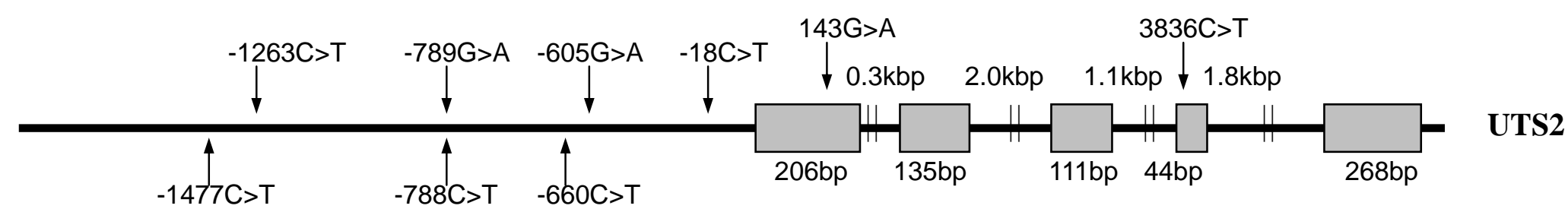

(b)

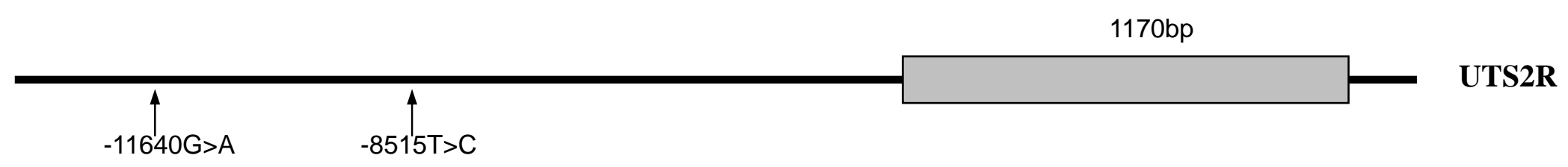




\section{Figure 2}

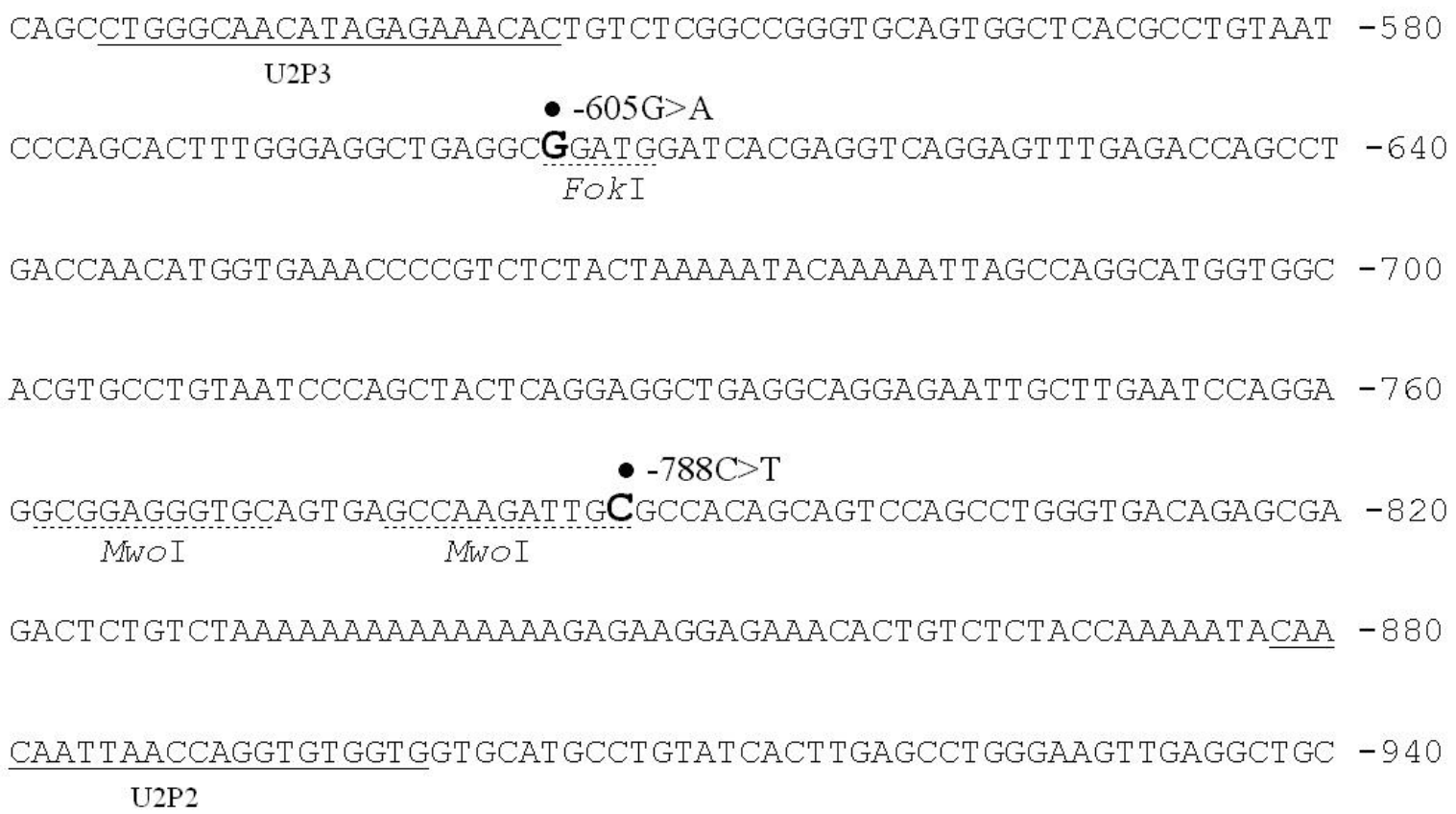


Figure 3

(a)

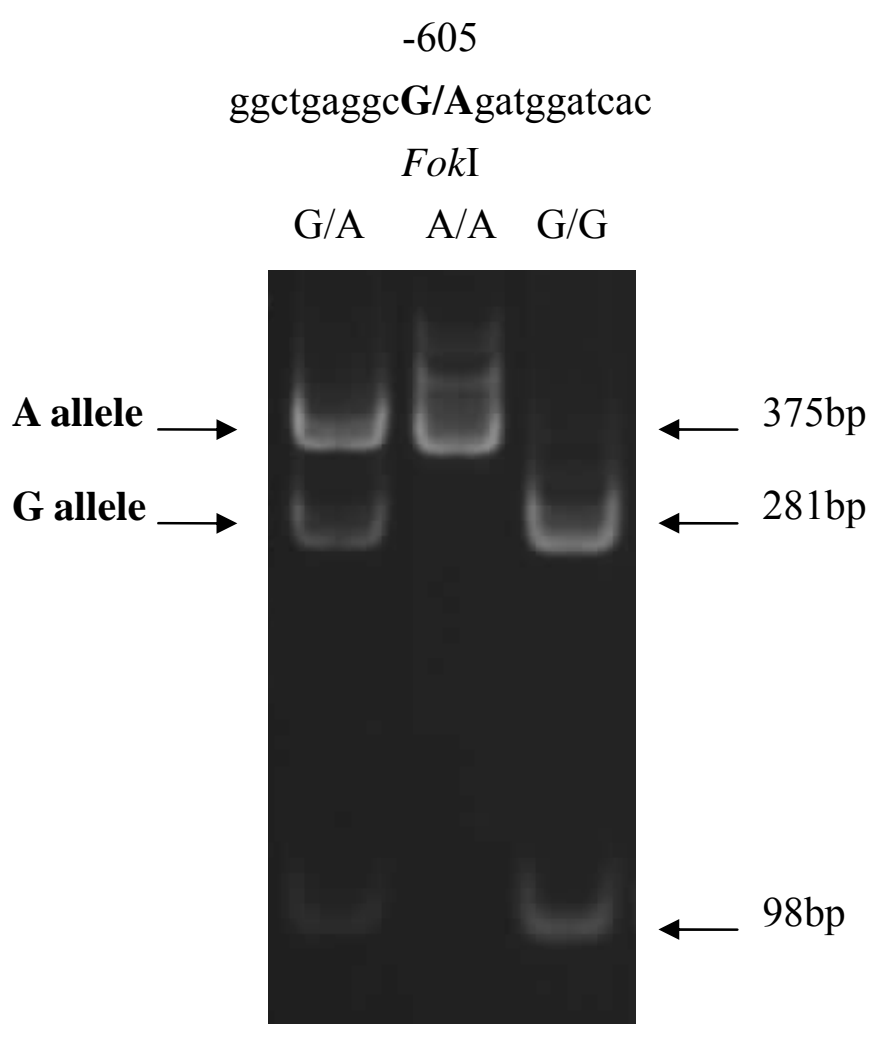

(b)

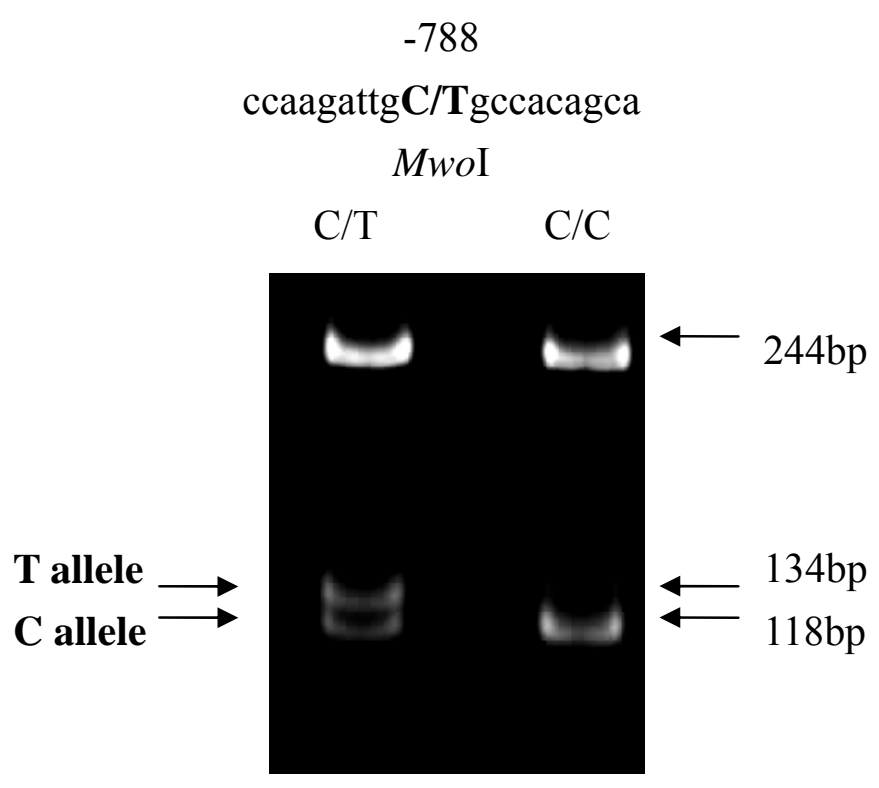

